\title{
COMMENTARY
}

\section{Optimal blood glucose control in severely burned patients: a long way to go, but one step closer}

\author{
Lars-Peter Kamolz ${ }^{* 1}$, Thomas Pieber², Freyja M Smolle-Jüttner ${ }^{3}$ and David B Lumenta'
}

See related review by Jeschke, http://ccforum.com/content/17/4/232

\begin{abstract}
Over the past years there has been a significant decrease in mortality and morbidity in patients suffering from severe burns due to improved burn wound management and approaches in critical care. Survival is no longer the exception, but unfortunately death still occurs. One of the key elements concerning state-of-the-art burn care is blood glucose control and insulin therapy; it is well known that burninduced hyperglycaemia is associated with adverse clinical outcomes. However, controversy for insulin therapy and tight glycaemic control in critically ill and burn patients exists. The increased incidence of hypoglycaemia is the dominant argument against this treatment, because hypoglycaemia is also associated with an increased risk for death in critically ill patients. Taking all current data together, insulin therapy appears both a friend and a foe in the treatment of ICU patients. In order to overcome the limits of tight glycaemic control resulting from hypoglycaemic episodes, current efforts have been directed towards the development of protocols allowing for implementation of clinically feasible and safe guidelines. Among the strategies addressing this problem are closed loop techniques, which are supported by studies demonstrating their capability of exerting tight glycaemic control without the risk of developing hypoglycaemic episodes. Although closed loop techniques have become readily available, we require further evidence to ensure their safety in various ICU environments, notably in ICUS dealing with burn patients. Nonetheless, it is important to emphasise that glycaemic control and adequate insulin therapy are crucial factors for the final outcome (survival) and require our attention.
\end{abstract}

*Correspondence: lars.kamolz@medunigraz.at

'Division of Plastic, Aesthetic and Reconstructive Surgery, Research Unit for Tissue Regeneration, Repair and Reconstruction, Department of Surgery, Medical University of Graz, Auenbruggerplatz 29, A-8036 Graz, Austria

Full list of author information is available at the end of the article

\section{Introduction}

With great interest we have read the paper by Jeschke, providing a very helpful, current best-practice overview on blood glucose control in burned patients [1]. Blood glucose control is one of the key elements in critical burn care and treatment. Over the past years there has been a significant decrease in mortality and morbidity in patients suffering from severe burns due to improved burn wound management and approaches in critical care $[2,3]$. Survival is no longer the exception, but unfortunately death still occurs [2]. Hyperglycaemia is associated with adverse clinical outcomes; in particular, burned patients with poor glucose control had a significantly higher incidence of bacteraemia/fungaemia, exhibited enhanced catabolism, and demonstrated increased mortality rates [4].

Insulin is not just a molecule mediating glucose control, but can act as a therapeutic agent per se. Recent studies showed that insulin improved muscle protein synthesis and therefore post-burn lean body mass [5]. Furthermore, insulin increased protein synthesis in the skin, accelerated wound healing [6,7], and had a massive impact on inflammatory and acute phase responses [8]. Some of these metabolic influences were linked to cellular changes, improving intracellular hepatic ATP, glucose, and lactate levels post burn - all indicators for a positively balanced energy efficiency. In addition, a burnsepsis two-hit model demonstrated improved survival resulting from insulin's tweaking not just of the metabolic system but also the immune system. In sum, insulin's beneficial effects are procured on multiple levels, making it a fascinating agent in the treatment of burn patients.

However, controversy exists for insulin therapy and tight glycaemic control in critically ill and burn patients. The increased incidence of hypoglycaemia is the dominant argument against it, which is supported by a majority of related studies in the field. A recent retrospective study reported the relationship between mild $(<81 \mathrm{mg} / \mathrm{dl})$ to severe $(<40 \mathrm{mg} / \mathrm{dl})$ hypoglycaemic episodes and death, and found in patients with hypoglycaemic episodes that mortality was $36.6 \%$ compared with $19.7 \%$ in those who did not experience 
hypoglycaemia [9]. Despite the lack of evidence for a causal relationship, the NICE SUGAR trial group also proved hypoglycaemia to be associated with an increased risk for death in critically ill patients [10]. Taking all current data together, insulin therapy appears both a friend and a foe in the treatment of ICU patients [11].

To overcome the limits of tight glycaemic control resulting from hypoglycaemic episodes, current efforts have been directed towards the development of protocols allowing for implementation of clinically feasible and safe guidelines [11]. Among the strategies addressing this problem are closed loop techniques [12-14], which are supported by studies demonstrating their capability of exerting tight glycaemic control without the risk of developing hypoglycaemic episodes. Although closed loop techniques have become readily available, we require further evidence to ensure their safety in various ICU environments, notably in ICUs dealing with burn patients.

With regard to optimal blood glucose levels, Jeschke evoked blood glucose levels of $130 \mathrm{mg} / \mathrm{dl}$ to be an ideal target [1]. This target reduces the risk for developing hypoglycaemic states as well as avoiding protein glycolysation at levels $\geq 150 \mathrm{mg} / \mathrm{dl}$, which is in agreement with current sepsis guidelines and is supported by various meta-analyses.

Because of the raised awareness of hypoglycaemia being an unwanted side effect of tight glycaemic control, current guidelines for the treatment of either critically ill, septic, trauma, or burn patients have been calling for less strict glucose control regimes supporting blood levels of 130 to $150 \mathrm{mg} / \mathrm{dl}$ [15]. Interestingly, burn patients have a higher incidence of hypoglycaemic events as compared with other patient populations, which is predominantly related to the special nature of the injury triggering a cascade of catabolic events. In addition, burn patients pose many difficulties in maintaining adequate tight glycaemic ranges resulting from feeding interruptions and variability in gastrointestinal tolerance. Owing to the requirement for almost weekly operations and daily dressing changes, enteral nutrition needs to be stopped occasionally - further disrupting the gastrointestinal motility, and complicating adjustments [15]. Furthermore, hyperbaric oxygen, which has been advocated as an adjuvant treatment option in burn care, has also been shown to increase peripheral sensitivity to insulin [16].

In conclusion, it is important to emphasise that glycaemic control and adequate insulin therapy are crucial factors that require our attention for improving the outcome of severely burned patients in the future. At the same time, we must consider the use of management strategies minimising the risk of triggering iatrogenic hypoglycaemic events. A glucose range of 90 to $140 \mathrm{mg} /$ $\mathrm{dl}$ therefore seems ideal for treating burn patients.
Competing interests

The authors declare that they have no competing interests.

\section{Author details}

'Division of Plastic, Aesthetic and Reconstructive Surgery, Research Unit for Tissue Regeneration, Repair and Reconstruction, Department of Surgery, Medical University of Graz, Auenbruggerplatz 29, A-8036 Graz, Austria.

2Division of Endocrinology and Metabolism, Department of Internal Medicine, Medical University of Graz, Auenbruggerplatz 15, A-8036 Graz, Austria.

${ }^{3}$ Division of Thoracic and Hyperbaric Surgery, Department of Surgery, Medical University of Graz, Auenbruggerplatz 29, A-8036 Graz, Austria.

Published: 8 October 2013

\section{References}

1. Jeschke MG: Clinical review: Glucose control in severely burned patients current best practice. Crit Care 2013. 17:232.

2. Williams FN, Herndon DN, Hawkins HK, Lee JO, Cox RA, Kulp GA, Finnerty CC, Chinkes DL, Jeschke MG: The leading causes of death after burn injury in a single pediatric burn center. Crit Care 2009, 13:183.

3. Kamolz LP: Burns: learning from the past in order to be fit for the future. Crit Care 2010, 14:106.

4. Gore DC, Chinkes D, Heggers J, Herndon DN, Wolf SE, Desai M: Association of hyperglycemia with increased mortality after severe burn injury. J Trauma 2001, 51:540-544.

5. Thomas SJ, Morimoto K, Herndon DN, Ferrando AA, Wolfe RR, Klein D, Wolf SE: The effect of prolonged euglycemic hyperinsulinemia on lean body mass after severe burn. Surgery 2002, 132:341-347.

6. Pierre EJ, Barrow RE, Hawkins HK, Nguyen TT, Sakurai Y, Desai M, Wolfe RR, Herndon DN: Effects of insulin on wound healing. J Trauma 1998, 44:342-345.

7. Pierre E, Barrow RE, Sakurai Y, Wolfe RR, Herndon DN: Structural effects of insulin on wound healing. Plastic Surg 1996, 36:743-745.

8. Jeschke MG, Klein D, Herndon DN: Insulin treatment improves the systemic inflammatory reaction to severe trauma. Ann Surg 2004, 239:553-560.

9. Egi M, Bellomo R, Stachowski E, French CJ, Hart GK, Taori G, Hegarty C, Bailey M: Hypoglycemia and outcome in critically ill patients. Mayo Clin Proc 2010, 85:217-224.

10. Finfer S, Liu B, Chittock DR, Norton R, Myburgh JA, McArthur C, Mitchell I, Foster D, Dhingra V, Henderson WR, Ronco JJ, Bellomo R, Cook D, McDonald E, Dodek P, Hebert PC, Heyland DK, Robinson BG: Hypoglycemia and risk of death in critically ill patients. N Engl J Med 2012, 367:1108-1118.

11. Andel D, Kamolz LP: Blood glucose control in critically ill patients. Minerva Anestesio/ 2012, 78:975-976.

12. Feichtner F, Mader JK, Schaller R, Schaupp L, Ellmerer M, Korsatko S, Kondepati VR, Heise HM, Wilinska ME, Hovorka R, Pieber TR: A stepwise approach towards closed-loop blood glucose control for intensive care unit patients: results from a feasibility study in type 1 diabetic subjects using vascular microdialysis with infrared spectrometry and a model predictive control algorithm. J Diabetes Sci Technol 2011, 5:901-905.

13. Yatabe T, Yamazaki R, Kitagawa H, Okabayashi T, Yamashita K, Hanazaki K, Yokoyama M: The evaluation of the ability of closed-loop glycemic control device to maintain the blood glucose concentration in intensive care unit patients. Crit Care Med 2011, 39:575-578.

14. Van Herpe T, De Mor B, Van den Berghe G: Towards closed-loop glycaemic control. Best Pract Res Clin Anaesthesiol 2009, 23:69-80.

15. Jeschke MG, Kraft R, Emdad F, Kulp GA, Williams FN, Herndon DN: Glucose control in severely thermally injured pediatric patients: what glucose range should be the target? Ann Surg 2010, 252:521-528.

16. Wilkinson D, Chapman IM, Heilbronn LK: Hyperbaric oxygen therapy improves peripheral insulin sensitivity in humans. Diabet Med 2012 29:986-989.

doi:10.1186/cc12733

Cite this article as: Kamolz LP, et al:: Optimal blood glucose control in severely burned patients: a long way to go, but one step closer. Critical Care 2013, 17:1005. 